\title{
ENTREVISTA: SOMOS TODOS MEXICANOS: UMA CONVERSA COM MURILO SEABRA
}

\author{
We are all Mexican: An interview with Murilo Seabra
}

\author{
Murilo Seabra* e Arthur Xavier**
}

\section{INTRODUÇÃO}

Por que não se estuda pensadores brasileiros nos cursos de filosofia? Onde é que eles estão? E o problema da falta de pensadores brasileiros nos cursos de filosofia é um problema que afeta apenas a comunidade filosófica brasileira? Ou o que temos aqui é a expressão local e particular de um problema político mais geral? Na seguinte entrevista, realizada por e-mail entre 22 de maio e 31 de julho de 2019, Murilo Seabra fala do estranhamento que causa a expressão "filosofia brasileira", das dificuldades objetivas e subjetivas que quem sai dos trilhos precisa enfrentar, e nos pede para pararmos de bater continência política e intelectual para as potências hegemônicas.

Palavras-chave: geopolítica do saber; justiça epistêmica; filosofia no Brasil

Arthur Xavier: É possível traçar a genealogia do pensamento filosófico à brasileira? É evidente a presença europeia, marcadamente francesa, inclusive na forma que lemos autores como Hegel, por exemplo. A despeito disso, há a possibilidade de nos subtrairmos a essas influências? E se nos subtrairmos a elas, pode restar, ainda, algum pensamento original?

Murilo Seabra: Antes de responder sua pergunta, quem sabe até mesmo ao invés de respondê-la, talvez seja interessante examinar como ela tende a atingir os membros da comunidade brasileira de filosofia no plano emocional. Isto é, talvez seja melhor tomá-la não como uma pergunta sobre o meu ponto de vista particular, mas como uma pergunta sobre o ponto de vista da comunidade brasileira de filosofia de maneira geral, ponto de vista que, apesar de já não ter sobre mim a mesma força que tinha antes, continua, de certa forma, influindo sobre o meu modo de pensar. Ou talvez seja melhor falar não em "ponto de vista", mas em "sentimento de vista", em "pathos

\footnotetext{
${ }^{*}$ Doutor em filosofia pela La Trobe University, Melbourne, Austrália. Email: murilorseabra@gmail.com

** Formando em direito pela Universidade Católica de Pernambuco, Recife, Brasil. E-mail: arthuroxr@ hotmail.com 
de vista”. Porque aquilo que interessa mesmo não é o que nosso intelecto tem a dizer. Aquilo que interessa é o que as nossas emoções têm a dizer.

Na pele da sua pergunta está inscrita uma divisão geográfica bastante precisa. De um lado, a França, a Alemanha, a Europa. Ou mais especificamente, o norte atlântico. Do outro lado, o Brasil e o resto do mundo, em todos os sentidos da palavra "resto". E além dessa divisão geográfica, a sua pergunta aponta também para uma divisão epistêmica entre influenciadores e influenciados, entre mestres e aspirantes, entre escritores e leitores, entre desbravadores e seguidores. Essas duas divisões, a geográfica e a epistêmica, que se reforçam mutuamente, estão firmemente gravadas nas entranhas dos membros da comunidade filosófica brasileira, formando os sulcos e reentrâncias por onde correm seus pensamentos, projetos e desejos. Não estou dizendo que você está sendo dualista ao opor a França ao Brasil, o norte atlântico ao resto do mundo. Estou dizendo que você está captando algo com a sua pergunta. Você está captando um dualismo que está aí presente, um dualismo que está dado. A oposição entre a França e o Brasil, entre o norte atlântico e o resto do mundo, é uma oposição que está marcada à ferro e fogo na mentalidade acadêmica brasileira. Apesar de não pensarmos de maneira dualista, sentimos de maneira dualista. $\mathrm{O}$ que eu sinto quando você fala em filosofia à brasileira? $\mathrm{O}$ que eu sinto quando você se refere à Europa e à França? O que eu sinto quando você fala em Hegel? E quando você fala em originalidade? Não parece meio estranho, meio destoante, falar em originalidade quando o assunto é a filosofia brasileira? Não parece mais natural falar em originalidade quando o assunto é a filosofia francesa?

É justamente por me parecer natural pensar em termos de originalidade acerca do pensamento europeu que fiz essa pergunta. É claro que se, por um lado, o aspecto emocional pode ser usado como diagnóstico, por outro, o intelecto serve como seu porta-voz. É justamente pela presentificação dessa ausência - ou seja, por emocionalmente reconhecer como faz falta, para um povo, a autonomia intelectual - que busco uma semente brasileira de pensamento. Sendo assim, consciente da estranheza e até do ressentimento que habitam essa falta, pergunto: onde está nosso pensamento? Pois, ao menos para mim, meu "sentimento de vista" se encontra marejado, justamente pela carência desta autonomia - isto é, de uma originalidade filosófica brasileira. 
Acho que temos algo bastante sério aqui. Não temos nenhum problema com a ideia de artistas brasileiros originais. A coisa não parece estranha. A coisa não é sentida como estranha. Temos expoentes brasileiros na música, na literatura, na arquitetura. Até mesmo nas artes marciais, graças à família Gracie. Mas não temos nenhum nome na filosofia brasileira comparável aos nomes que temos em outras áreas. E também não temos espaço interior, isto é, espaço em nossas subjetividades, para um grande nome brasileiro na filosofia. A coisa não é apenas inconcebível - mais do que uma afronta ao pensamento, ela é uma afronta aos nossos sentimentos, educados a considerar a ideia de uma filosofia brasileira como uma piada. Estou enfatizando aqui o sentir porque não adianta muita coisa simplesmente achar, pensar ou acreditar que podemos, sim, ter pensadores brasileiros originais. O pensar é um começo. Ele já indica uma luta interior. Ele já é um sinal da busca por emancipação das estruturas coloniais incrustadas na carne do nosso ser. Aliás, não existe outro ponto de partida. A nossa subjetividade já está entregue. Os nossos sentimentos já estão entregues. Os nossos desejos, sonhos e projetos já estão entregues. Então a gente tem que começar pensando sobre a situação - não só exterior, mas também interior - em que nos encontramos.

Mas o Vladimir Safatle, por exemplo, não é um filósofo brasileiro? Ele não é um grande filósofo brasileiro? Ele não está para a filosofia assim como a Clarice Lispector está para a literatura? E como o Djavan está para a música? E o Oscar Niemeyer para a arquitetura? Bom, ele tem uma visibilidade muito grande. O quanto ela vai durar, é difícil saber. Porque não é por causa de sua filosofia e sim por causa do seu engajamento intelectual que ele tem visibilidade. Habermas é famoso por causa da teoria da ação comunicativa. Sartre, por causa do existencialismo. Derrida, por causa da desconstrução. Husserl, por causa da fenomenologia. Searle, por causa da teoria dos atos de fala. Mas por que o Safatle é famoso na cena intelectual brasileira? Por causa das intervenções que ele faz na esfera pública. A mesma coisa vale para a Marilena Chauí e em grau menor também para o Roberto Machado. A fama que possuem não provém de suas ideias e teorias. A Chauí é uma grande intelectual pública e uma grande estudiosa da filosofia europeia moderna, especialmente de Spinoza. O Machado é um grande divulgador do pós-estruturalismo no Brasil. Então eles não são conhecidos por conta de suas próprias ideias e teorias. Eles não são conhecidos por conta de seus próprios esforços filosóficos. Eles são conhecidos por terem capitalizado sobre os esforços filosóficos dos outros.

A situação é meio trágica. Os nossos filósofos mais conhecidos estão para a filosofia assim como a banda Os Besouros está para The Beatles. Eles são intérpretes, não compositores. Não é que não exista filosofia no Brasil. Ela existe, apenas não na filosofia. Aliás, talvez o maior filósofo brasileiro da atualidade seja o Eduardo Viveiros de Castro, que trabalha primariamente com etnologia, não com filosofia. Apesar de 
também intervir na esfera pública, ele é famoso, observe a diferença, por causa do modelo interpretativo que desenvolveu junto com a Tânia Stolze Lima - o chamado "multinaturalismo" ou "perspectivismo ameríndio". Ele é conhecido por causa de sua obra intelectual, não por causa de sua militância política. Aliás, acho que a sua obra intelectual dá força para a sua militância política. Ela chama atenção para a sua militância política. O que acontece com o Safatle e a Chauí é exatamente o contrário. Parece que é a militância deles que chama atenção para suas obras. Aliás, foi precisamente por causa da postura política deles que fiquei com vontade de lê-los. Como são interessantes politicamente, a gente presume que eles são também interessantes intelectualmente. Mas uma coisa não se segue da outra. Não é que suas obras não tenham valor. Elas têm valor, sim. Mas é um valor comparável ao das músicas tocadas pela banda Os Besouros.

Não me entenda mal. O trabalho que o Safatle faz como intelectual público, por exemplo, é extraordinário. É preciso ter muita coragem para criticar abertamente, quase chamando para a porrada, um presidente que já falou que durante a ditadura os militares deveriam ter matado mais umas 30 mil pessoas, que está trabalhando para flexibilizar o porte de armas, que quer facilitar as coisas para que até crianças possam frequentar escolas de tiro e que é indisfarçavelmente conectado a assassinos. E para piorar as coisas, entre os seus seguidores não há apenas robôs. Há também zumbis. Eles estão à solta, não têm nada ou muito pouco na cabeça e são uma parte considerável da população. Por mais que sejam desprezíveis, eles não podem ser desprezados. Uma coisa é uma pessoa como eu, que não tem praticamente nenhuma inserção pública, criticar o Bolsonaro e seus apoiadores. Outra coisa é o Safatle criticá-lo, e criticá-lo como fez recentemente, sem meias-palavras, na Folha de São Paulo. É realmente preciso ter muita coragem. A retaliação pode vir de qualquer lado.

Também não estou dizendo que é mais importante trabalhar no desenvolvimento de ideias e teorias do que participar do debate público, o que seria como dizer que é mais importante construir túneis do que construir pontes. Cada coisa tem o seu lugar. Cada coisa tem a sua função. $O$ que não pode haver é uma completa falta de conexão entre a filosofia e a realidade social circundante - entre a academia e o mundo do qual ela faz parte. Aliás, uma das formas de se avaliar a força de uma teoria é medindo para onde ela dirige o debate público, para onde ela dirige a realidade - e os efeitos que ela tem sobre nossa subjetividade. O trabalho que o Safatle está fazendo, apesar de não ser um trabalho propriamente filosófico, é absolutamente fundamental. Ele está lutando pelo significado da realidade. A Eliane Brum e a Tatiana Merlino, que 
não vieram da filosofia, mas do jornalismo, também estão na mesma luta e também são intelectuais públicas sensacionais. O mesmo vale para o Luis Nassif e o Breno Altman. Se não tivéssemos pessoas como eles, estaríamos perdidos. Não estaríamos apenas filosoficamente perdidos, estaríamos perdidos em todos os sentidos, e muito mais perdidos do que já estamos. As coisas seriam muito mais fáceis para os Olavos de Carvalho e Reinaldos Azevedo da vida - e consequentemente também para os Bolsonaros, os Guedes e os Moros da vida -, que claramente chegaram onde chegaram não por mérito e sim por demérito.

Então temos músicos, escritores, arquitetos e intelectuais públicos notáveis. O que não temos são pensadores notáveis. Não temos um Marx. Não temos um Sartre. Não temos um Fanon. Não temos um Althusser. Isto é, não temos filósofos - estou falando de filósofos, não de comentadores - que sejam ao mesmo tempo intelectualmente inovadores e publicamente reconhecidos. Temos filósofos famosos, sim. Mas eles não estão à altura de sua fama. É possível que tenhamos desbravadores no campo do pensamento espalhados pelos quatro cantos do Brasil. Mas eles não são conhecidos. E não basta que as coisas que você faz tenham qualidade. É imprescindível que tenham qualidade. Mas não basta. É preciso também que haja um meio capaz de percebê-las, reconhecê-las, acolhê-las, desenvolvê-las. Então o simples fato de que a ideia de um europeu original é mais palatável do que a ideia de um brasileiro original é realmente preocupante.

A filosofia é um curso por onde passam muitas pessoas. Talvez não tantas quanto passam por cursos mais procurados - como os cursos de pedagogia, publicidade e administração -, mas nem por isso deixa de ser um curso por onde passam muitas pessoas. Ele tem uma certa influência sobre a sociedade. Ele deixa marcas nas mentes que cursam suas disciplinas, marcas que depois vêm à tona em almoços com a família, churrascos com os amigos, conversas de bar e reuniões de trabalho. Ele forma professores que por sua vez formam dezenas, centenas, milhares de estudantes. Então a interdição contra os brasileiros qua sujeitos epistêmicos e do Brasil qua objeto de análise é uma interdição que tem consequências bastante sérias, que contribuem para limitar a filosofia à vida acadêmica, mas que não se limitam à vida acadêmica da filosofia. Quando você interdita os sujeitos epistêmicos brasileiros, você acaba interditando também os temas brasileiros. Pois são os brasileiros que melhor sabem manuseá-los. E quando você interdita os temas brasileiros, você acaba interditando também os sujeitos epistêmicos brasileiros. Pois eles são os temas que os brasileiros melhor sabem manusear. E assim o círculo se fecha.

$\mathrm{Na}$ verdade, a interdição não é só contra os elementos básicos sem os quais não pode haver jamais uma filosofia brasileira. A interdição é contra todos os sujeitos epistêmicos que não sejam sujeitos epistêmicos do norte atlântico e contra todos os 
temas que não sejam temas ditados pelo norte atlântico - e completando o quadro, também contra todas as metodologias que não tenham previamente recebido o aval do norte atlântico. Os sujeitos epistêmicos não sancionados pelo norte atlântico não são dignos de atenção, os temas não sancionados pelo norte atlântico não são dignos de interesse e os métodos não sancionados pelo norte atlântico não são dignos de confiança. Não vale a pena escutar os primeiros, falar sobre os segundos e empregar os terceiros. Não vale a pena. E há, sim, uma pena. Aliás, uma pena alta.

A voz que todo mundo quer ouvir é a voz do norte atlântico. E o que todo mundo quer é que ela fale sobre o norte atlântico. Isto é, a gente quer ouvir o norte atlântico falando sobre si mesmo. A gente quer ouvir a voz legítima falando sobre aquilo que é legítimo falar. Talvez seja interessante lembrar aqui do que o Žižek diz sobre os vibradores. Podemos aceitar o sexo com todos os seus fluidos e odores, isto é, com tudo que ele trás de real, incluindo a materialidade da pessoa com quem se vai para a cama - ou então podemos usar apetrechos e mais apetrechos intermediários para progressivamente nos afastarmos do real e nos aproximarmos do sexo ideal. O problema é que agora existem vibradores também para homens, não só para mulheres, o que significa que podemos enfiá-los um no outro e deixá-los vibrando sozinhos. Ou seja, agora é possível transcender completamente o real. Você pode fazer sexo não apenas sem o corpo de outra pessoa, mas também sem o seu próprio corpo. A realidade é dispensável. As pessoas são dispensáveis. Pois o jogo se joga por si mesmo. E é isso o que se faz nos departamentos de filosofia brasileiros, uma filosofia sem filosofia e sem brasileiros. Uma filosofia de dar inveja em termos quantitativos e de dar vergonha em termos qualitativos. Uma filosofia sem personalidade, sem seiva, sem substância. Uma filosofia pro forma.

A impressão de que não se pode filosofar sobre temas brasileiros está em perfeita continuidade com o horror da filosofia ao mundo sensível - que, por sua vez, se harmoniza perfeitamente bem com o horror dos brasileiros aos imigrantes haitianos, com o horror das elites às classes baixas nos aeroportos, com o horror a empregadas domésticas no elevador social, com o horror a mulheres em posição de comando e com o horror das novas gerações aos pelos pubianos. Em todos casos temos aqui um horror à "invasão vertical dos bárbaros".

E acho que esse é o maior problema do Safatle. Quando o Rafael HaddockLobo propôs uma abertura do pensamento às heranças ameríndias e afrobrasileiras, ele reagiu de maneira completamente horrorizada, como se houvesse uma intenção perversa por trás da tentativa de superar o nosso colonialismo acadêmico. Para mim, foi 
uma decepção. O Haddock-Lobo estava radicalizando o discurso do Porchat. E o Safatle, tentando contê-lo. Eu realmente não entendo como ele consegue, por um lado, criticar a exclusão econômica dos afrodescendentes, e, por outro, criticar a inclusão deles como vozes ativas na economia do saber. A conta não bate. Tudo o que podemos fazer é esperar que um dia ele siga os passos do Porchat e faça também um mea culpa. Tudo o que podemos fazer é esperar que ele reconheça que em seu racismo epistêmico também existe um projeto de nação. A gente tem que destruir o Império Romano. A gente tem que acabar com o purismo filosófico.

No fundo, tudo se reduz à rejeição do nosso parentesco com os macacos - que se traduz na rejeição dos povos historicamente associados aos macacos. Trata-se de uma rejeição da nossa natureza - e também da natureza propriamente dita. Até mesmo a naturalidade é rejeitada. Você não pode escrever de maneira natural. Você tem que fazer pose. Você tem que falar em Gedankenexperimente, em Weltanschauungen, em Übermenschen. Nós, brasileiros, somos macacos. Nós, brasileiros, somos natureza. Temos que aprender inglês. Temos que aprender francês. Temos que aprender alemão. Só é possível filosofar em alemão. Então quando rejeitamos os sujeitos e temas brasileiros, o que estamos fazendo é uma espécie de depilação. O que estamos fazendo é um esforço para nos aproximarmos da civilização - para nos tornamos menos animais e mais humanos. Assim como nos depilamos para transar, nos desbrasileiramos para escrever. O Brasil é real demais, exuberante demais, caótico demais, sujo demais, empírico demais, viscoso demais, selvagem demais, primata demais, imprevisível demais, violento demais para merecer a atenção da filosofia. É preciso transcendê-lo. Por mais que ele fale da imanência, portanto, o horror do Safatle à invasão epistêmica dos bárbaros mostra que ele é um partidário da transcendência - junto com praticamente toda comunidade acadêmica brasileira. O Brasil não pode ser tematizado. Não pela filosofia. Ele está fadado a degradá-la, a descaracterizá-la. Consequentemente, o que se faz nos departamentos de filosofia brasileiros é sempre uma filosofia transcendente, civilizada, oxigenada, alisada - e depilada. O norte atlântico é civilizado, puro, espiritual, racional, adulto, masculino, abstrato e universal. O resto do mundo é bárbaro, impuro, corporal, emocional, infantil, feminino, concreto e particular. Ele é a matéria sobre a qual se aplica, não da qual se deriva pensamento.

Então ao invés de serem equipados para pensar criticamente sobre o genocídio indígena, por exemplo, os estudantes brasileiros de filosofia são condicionados a acreditar - até mesmo a sentir - que o único evento de desumanização e assassinato em massa que se pode legitimamente tematizar na filosofia é o Holocausto. Nem mesmo o que os israelenses fazem hoje com os palestinos pode ser discutido. Por quê? Porque os filósofos acadêmicos brasileiros só falam do mundo político e social por meio daquilo que falam os filósofos ocidentais de renome, que intermediam - e fiscalizam - a nossa 
relação com a realidade. Você pode falar do Holocausto, da Revolução Francesa e do cristianismo. Mas não do genocídio indígena, de Canudos ou das religiões de matriz africana. Não dentro da disciplina de filosofia. Seria nacionalismo, como disse o Safatle, coisa que ele execra com todas as letras, sem fazer discriminações que são, sim, relevantes - e sem perceber que não é só na economia que faz sentido falar em entreguismo. Depois de serem assassinados fisicamente, os povos indígenas são também assassinados intelectualmente. Eles são rebaixados pela filosofia acadêmica como próximos demais do mundo empírico - eles são rebaixados como primitivos demais para terem uma relação sinergética com o pensamento acadêmico.

Então apesar de enfrentar o Bolsonaro com a cabeça erguida, o Safatle também bate continência para o norte atlântico. A diferença é que sua subjetividade não está moldada à imagem e semelhança dos Estados Unidos e sim à imagem e semelhança da França. Ou seja, existe uma certa semelhança entre os dois, uma semelhança que não deve ser exagerada, mas que também não pode ser ignorada. O Bolsonaro é conservador desde as camadas mais profundas até as camadas mais superficiais do seu ser. O Safatle é bastante afiado no plano político. Mas ele é conservador no plano cognitivo. Como intelectual público, ele é admirável. Mas na condição de profissional da filosofia, ele é um eurofundamentalista, como diria o Renato Noguera.

Se a gente parar para pensar, a gente vai ver que aquilo que os nossos professores de filosofia estão fazendo é essencialmente ridicularizar e tornar as coisas difíceis para os nossos Djavans, Criolos e Zero Quatros - e congratular e gratificar os nossos Os Besouros e NX Zeros. Você só tem duas opções, ser um mero intérprete dos grandes nomes da música internacional ou compor músicas que não destoem da paisagem sonora internacional. Você não pode fazer o que Chico Science fez. Ele é precisamente o modelo do que não se deve fazer. Os nossos melhores compositores os nossos compositores verdadeiramente originais e verdadeiramente antenados à realidade circundante - são repelidos pela academia.

Então a gente tem que desconfiar da ideia de "filosofar com", que os professores de filosofia brasileiros costumam usar para justificar a sua subserviência em relação ao pensamento ocidental. Eles enfatizam a importância de não nos isolarmos intelectualmente e de conhecermos o que está aí. E às vezes chegam até a dizer que não estão comentando Foucault, mas filosofando com Foucault - e que, na verdade, não há outra forma de se filosofar. Acontece que é sempre com Foucault que eles filosofam, nunca com Odera Oruka ou Davi Kopenawa, nunca com Vandana Shiva ou Walter Mignolo. É sempre com Foucault, Derrida, Searle ou Davidson. Eles dizem que é 
preciso "fazer música com". Mas quando você observa como eles implementam a ideia de "fazer música com", você percebe que só se pode fazer música "com rock", jamais "com maracatu".

Existem exceções, é verdade. O Noguera já está nadando contra a correnteza - isto é, contra o eurofundamentalismo brasileiro - a braçadas largas. Mas o megafone ainda está nas mãos de professores como o Safatle, que acham, por exemplo, que foi graças à Revolução Francesa que houve a Revolução Haitiana, como se os escravos tivessem permanecido obedientes em seus papéis até que um dia ouviram os franceses falando em liberté, égalité e fraternité - tendo sido, portanto, emancipados espiritualmente por seus carrascos. O que temos aqui não é apenas de uma distorção dos fatos. É uma verdadeira afronta à história. Os escravos haitianos já tinham se rebelado contra os franceses muito antes de ouvirem seus calculados gritos de guerra. Mas o Safatle parece ser incapaz de perceber e se distanciar do discurso autocongratulatório do ocidente - muito bem articulado por Hegel e atualmente defendido de forma apaixonada por Žižek. É apenas no acervo cultural do ocidente que se deve apostar. É nele que está a saída para a enrascada em que ele nos meteu. Tem algo errado aí.

A sua pergunta, em certo sentido, condensa uma saga cujo desfecho ainda não conhecemos. O pensamento filosófico brasileiro conseguirá um dia se afirmar de maneira autônoma? Isto é, ele poderá um dia vir a ser um pensamento no sentido estrito do termo? Evidentemente, a coisa não está indo bem. O novo governo é inimigo do pensamento. E também já não estava indo bem. Porque não dá para dizer que uma comunidade acadêmica que tem vergonha de si mesma e do meio onde vive está indo bem. Mas agora o projeto é proscrever o pensamento tout court, não só o pensamento maculado pelas impurezas brasileiras. Antes a gente tinha que lutar por uma filosofia mais antenada às nossas circunstâncias. Agora a gente tem que lutar até mesmo pela filosofia eurofundamentalista. Estamos passando por um novo 1964. A diferença é que não temos mais um Darcy Ribeiro. Então a gente tem um longo caminho pela frente. Se a esquerda acadêmica já não dava espaço para o pensamento, não é a direita que vai abri-lo. "Nós queremos uma garotada que comece a não se interessar por política", explicou o Bolsonaro. O problema é que a política é a categoria fundamental do pensamento.

A nossa tradição está no futuro, não no passado. Ela ainda está por ser feita. Temos que fazer o que os nossos professores não fizeram - e que ainda por cima nos disseram que não tínhamos capacidade de fazer. Temos que fazer o que nos desencorajaram - de forma sutil, mas eficiente - de fazer. Temos que fazer o que não podemos fazer. Temos que fazer não apenas um pensamento crítico, mas também um pensamento original. Aliás, as duas coisas andam juntas. Não há como dissociá-las. 
Para um pensamento ser original, ele precisa ser crítico. E para ser crítico, radicalmente crítico, ele tem que ser original.

E já tem gente colocando a mão na massa - especialmente nas margens da academia, que é onde o pensamento, livre do produtivismo e da necessidade de usar terno e gravata, consegue passar mais tempo consigo mesmo. O pouco que li do Luiz Alberto Thomé Speltz Filho, por exemplo, me deixou impressionado. Ele não está no mainstream, é verdade. Ele não é muito conhecido - até porque ainda não publicou muito. Mas a gente tem que lembrar que assim como existem músicas de altíssima qualidade que não passam nas rádios - acho que está bastante claro que as músicas mais tocadas estão longe de ser as melhores -, também existem ideias, teorias e formas de análise interessantes, consistentes, iluminadoras e profundas - e às vezes até radicalmente inovadoras - que são sistematicamente ignoradas pelo circuito acadêmico oficial. A qualidade é uma coisa. A visibilidade é outra. Evidentemente, as rádios não querem que saibamos que as músicas que elas tocam não são necessariamente as melhores; pelo contrário, é importante para elas que acreditemos que o critério de seleção do material colocado no ar é perfeitamente justo e racional, isto é, que a visibilidade decorre da qualidade. Não é por causa do preconceito contra brasileiros que você não é lido. É porque você não tem nada a oferecer mesmo. Vivemos em uma sociedade meritocrática. Pelo menos, é o que dizem. Então não precisamos apenas de mais compositores. Também precisamos de rádios melhores.

\section{Há um caminho para elaboração autoral no esteio acadêmico? Ou as pessoas que desejam se insurgir contra a submissão intelectual brasileira devem procurar meios de capilarizar seu pensamento para fora do nicho universitário? Que estratégia poderia ser adotada para este tipo de movimento?}

$\mathrm{Eu}$ acho que todas as pessoas preocupadas com o pensamento - preocupadas com a sociedade, preocupadas com o mundo - se sentem naturalmente inclinadas a cruzar a fronteira entre a academia e a realidade circundante. Infelizmente, porém, tenho pensado mais em estratégias defensivas do que em estratégias ofensivas, isto é, mais em estratégias que permitam às pessoas genuinamente comprometidas com o pensamento sobreviverem no ambiente acadêmico do que em estratégias para empoderá-las e aumentar a visibilidade e o impacto de sua produção intelectual fora da academia. 


\section{Poderia compartilhar, então, o que faz a estratégia de defesa tão necessária? Qual é o risco que esse tipo de pensamento, ao ousar, chama para si? O que deve esperar aquele que se pôr a estes caminhos?}

Se você se tornar um estudioso de Hegel, se você escrever seu trabalho de conclusão de curso sobre Hegel, fizer um mestrado sobre Hegel, depois um doutorado, você vai ser recompensado de inúmeras maneiras - tanto objetivamente, porque os seus projetos e propostas de pesquisa terão mais chances de ser aprovados do que se você se tornar um estudioso de Hountondji ou de Oruka, quanto subjetivamente, porque você será consultado por seus colegas que não conhecem tanto Hegel, você será chamado para dar palestras, você será convidado para participar de coletâneas, você será visto e sentido como um pesquisador sério, numa palavra, você será valorizado.

$\mathrm{Eu}$ recentemente vi dois concursos para professor de filosofia em universidades brasileiras. Os candidatos tinham que passar por uma prova escrita e depois uma prova didática, como acho que é sempre o caso nas instituições públicas brasileiras. No primeiro concurso, os temas das provas seriam sorteados a partir de uma lista que incluía coisas como virtude em Aristóteles, moral em Kant, política em Hegel e poder em Foucault. Então se você passou a vida toda estudando Aristóteles, Kant, Hegel ou Foucault, você naturalmente já sai em vantagem em relação a quem dedicou seus anos de estudo a Hountondji ou Oruka. Do ponto de vista objetivo, do ponto de vista institucional, o seu conhecimento sobre Hegel tem valor. Ele serve como moeda de troca. O seu conhecimento sobre Oruka, ao contrário, não apenas tem pouco ou nenhum valor. Ele pode ter até um valor negativo. Se na sua apresentação sobre Hegel, você mencionar as críticas feitas por Marx ao seu pensamento, você poderá ganhar um ponto a mais por sua erudição. Mas se você mencionar o racismo de Hegel, se você falar dos filósofos africanos que analisam a relação entre o racismo e a filosofia moderna, você poderá perder pontos. Aliás, você poderá ser até acusado de anacronismo.

No segundo concurso, não havia nenhuma referência a autores, somente a temas. Não lembro mais quais eram, mas o que importa aqui é notar que você pode usar tanto Hegel quanto Hountondji para falar sobre a noção de razão, por exemplo. Você pode. Porque os dois disseram coisas relevantes sobre o problema da razão. Então você pode. Mas o fato de que você pode mencionar Hountondji, não significa que seja uma boa ideia mencioná-lo. Não havia nas regras do concurso nenhuma referência explícita à necessidade de se utilizar os grandes nomes do pensamento ocidental, muito menos à necessidade de não se mencionar autores latino-americanos, asiáticos ou africanos. É possível até que a comissão organizadora do concurso tenha decidido mencionar temas, mas não autores, justamente para convidar a referência a autores latino-americanos, asiáticos e africanos. Isto é, para trazer um pouco de justiça epistêmica para a academia. 
Mas é possível também que a abertura tenha sido apenas uma miragem. Talvez o uso de temas tenha sido uma estratégia para não deixar o candidato que se especializou em Kant em desvantagem em relação ao candidato que se especializou em Hegel, não para dar ao candidato que se especializou em Hountondji as mesmas chances de ser aprovado. Uma coisa é a abertura para diferentes autores, correntes e linhas de pensamento da tradição filosófica ocidental. Outra coisa bem diferente é a genuína abertura para autores, correntes e linhas de pensamento de regiões simbolicamente desprivilegiadas do globo.

Mas os obstáculos objetivos, os obstáculos institucionais e profissionais, não são os únicos obstáculos que atrapalham o caminho de quem sai da linha. $\mathrm{O}$ custo psicológico da rebeldia intelectual também é enorme. Eu entrei em depressão durante o meu doutorado e até deixei de ir para a universidade durante cerca de quatro meses simplesmente para me proteger dos ataques contínuos que sofria dos meus colegas. Você já ouviu falar que o feminismo é pura e simplesmente um machismo invertido? Trata-se de uma afirmação que não tem pé nem cabeça - que infelizmente se ouve cada vez mais por aí. $\mathrm{O}$ fato de que o feminismo critica e combate o preconceito contra mulheres não significa que ele seja um movimento que pretende subjugar, oprimir e cometer injustiças contra homens. Uma coisa não tem nada a ver com a outra. Da mesma forma, as pessoas que combatem o racismo não estão combatendo as pessoas de pele clara. Elas estão combatendo uma mentalidade - e uma realidade - que privilegia sistematicamente as pessoas de pele clara em detrimento das pessoas de pele escura. Felizmente, ainda é difícil encontrar nas humanidades pessoas que acham que o feminismo é um machismo invertido e que a luta contra o racismo é na verdade uma luta contra as pessoas de pele clara. Ainda é. Mas acho que a ascensão do Bolsonaro deixou bastante claro que as conquistas da esquerda não são conquistas definitivas. As universidades - e especialmente as humanidades - estão sob ataque. É possível que a ideia de que o feminismo é um machismo invertido volte a ganhar espaço até mesmo no ensino superior.

Então você pode imaginar a minha surpresa quando comecei a ouvir dos meus colegas que eu estava incorrendo numa espécie de machismo invertido. Eu havia desenhado um experimento para ver se a comunidade acadêmica de filosofia tendia a favorecer os autores dos países autorizados em detrimento dos autores dos países não autorizados. Eu estava tentando combater um tipo de preconceito que tem uma importância política muito grande e do qual ainda se fala muito pouco. Eu estava tentando trazê-lo à tona para criticá-lo. E o que aconteceu? Eu fui acusado de estar 
abraçando - e pior ainda, fomentando - o preconceito contrário. "Você não pode esquecer da grandiosidade do pensamento europeu", me advertiu um colega. A coisa não tem sentido. Até porque o pensamento europeu não corre nenhum risco de ser esquecido. É o pensamento latino-americano que está sendo esquecido. É o pensamento asiático. É o pensamento africano.

Uma das críticas mais absurdas e incoerentes que ouvi à minha pesquisa veio de um professor de lógica - um professor, aliás, bastante respeitado e influente no Brasil. O que eu fiz no meu experimento foi muito simples. Eu construí dois questionários virtualmente idênticos. Os respondentes tinham que avaliar uma série de textos curtos de acordo com critérios como originalidade, seriedade e consistência. $\mathrm{O}$ truque era que os textos atribuídos a autores europeus num questionário eram atribuídos a autores latino-americanos no outro questionário. E o que o meu crítico disse? Primeiro, ele disse que eu não poderia comparar os resultados dos dois questionários, pois eu os havia aplicado a grupos diferentes de pessoas, e, em seguida, ele recriminou minha metodologia por eu não ter usado um grupo de controle. Isto é, a crítica dele não foi apenas inadequada. Ela foi realmente uma crítica autocontraditória. Já que os resultados obtidos com dois grupos diferentes de pessoas não podem ser comparados, é fácil perceber que o acréscimo de um terceiro grupo só pode piorar as coisas.

Eu fiz uma lista de mais de vinte críticas sem pé nem cabeça que recebi de pessoas altamente qualificadas do ponto de vista acadêmico. O que achei intrigante é que elas não estavam dizendo coisas como "Murilo, você está errado. A capital da Austrália não é Camberra e sim Sydney", o que pelo menos teria feito sentido. O que elas estavam dizendo eram coisas como "Murilo, você está errado. A capital da Austrália não é Camberra. Na verdade, é a Grã-Bretanha que é a capital de Sydney”. Isto é, elas estavam dizendo coisas que não tinham sentido. Elas estavam dizendo coisas incoerentes. Mas como é que você desqualifica uma mulher que faz um trabalho original e interessante? Como é que você a coloca de volta em seu lugar quando o trabalho dela não é apenas original e interessante, mas também sólido e consistente? Só existe uma saída. Você tem que fazer uma crítica inconsistente, uma crítica que não se sustenta, uma crítica que se autocontradiz.

Uma outra crítica que ouvi também precisa ser mencionada aqui. O problema da minha pesquisa era que eu havia aplicado os questionários a pessoas diferentes. $\mathrm{O}$ que eu devia ter feito era aplicar o primeiro questionário para toda minha amostra de pessoas e em seguida, digamos três meses depois, o segundo questionário para toda amostra de novo. Eu não consegui acreditar no que estava ouvindo. Temos aqui um fenômeno que precisa ser explicado. Aliás, temos aqui um fenômeno que precisa ser antes de tudo documentado, descrito e nomeado. Quando um matemático olha para uma mulher de cima para baixo e diz que ela cometeu um erro básico ao dizer que $1+1=2$, 
porque a verdade é que $1+1=3$, não estamos simplesmente diante de uma crítica fraca ou sem fundamento. Estamos diante de algo muito mais estranho. Estamos diante de uma regressão cognitiva espantosa. E de uma regressão cognitiva que só pode ser explicada por meio de categorias políticas.

Então eu estava numa universidade que orgulhosamente se apresentava como fazendo parte das 400 melhores universidades do mundo - o que me causou, em certa ocasião, um ataque de risos -, sendo constantemente corrigido por pessoas altamente treinadas que me diziam coisas como "Na verdade, é a Grã-Bretanha que é a capital de Sydney" e "Na verdade, $1+1=3$ ", e que depois provavelmente saíam satisfeitas consigo mesmas, orgulhosas por terem ajudado um pobre estudante do Terceiro Mundo a superar sua ignorância congênita. Se a coisa tivesse acontecido somente uma, duas ou três vezes, acho que daria para falar em falta de sorte da minha parte. E se as críticas tivessem sido pelo menos coerentes, daria para explicá-las em termos de déficit de informação. Infelizmente, porém, a hipótese mais plausível parece ser a de que os meus colegas estavam tentando me colocar de volta no meu lugar. A gente já sabe, graças aos trabalhos de Claude Steele, que o mеи desempenho intelectual pode ser objetivamente afetado pelo simples fato de que pertenço a um grupo que é mal visto. Mas parece que o desempenho intelectual dos meus avaliadores também pode ser negativamente afetado - e de forma drástica - pelo simples fato de que pertenço a um grupo que é mal visto. As pessoas precisam ser colocadas de volta em seus lugares. E para cada esfera da sociedade em que você se encontra - seja no setor privado, seja numa reunião de trabalho, seja na academia -, há um lugar especial para você.

Se o meu doutorado tivesse sido sobre Hegel, se eu tivesse apenas chovido no molhado, acho que as coisas teriam sido diferentes. Os meus colegas não teriam avançado sobre mim como gangues de rua em busca de sangue. Eles não teriam usados argumentos - se é que se pode chamar "Na verdade, é a Grã-Bretanha que é a capital de Sydney" de argumento - como tacos de beisebol para me fazer lembrar da minha posição subordinada na economia do saber. O que os estudantes do Terceiro Mundo têm que fazer, o que os estudantes de pele escura têm que fazer, é justamente aprender com o Primeiro Mundo. Não é questionar a política por trás da circulação pública do pensamento, muito menos a política do pensamento qua processo interior. Então se eu tivesse feito meu doutorado sobre Hegel, Nietzsche, Heidegger, Wittgenstein, Carnap, Quine, Davidson, Searle, Foucault, Deleuze, Derrida ou Habermas, eu teria permanecido no meu lugar e os meus colegas não teriam sentido necessidade de me alfinetar. 
Evidentemente, escrever uma tese de doutorado não é uma tarefa fácil. E fazêlo sob olhares reprovadores, precisando ouvir continuamente coisas como "Na verdade, é a Grã-Bretanha que é a capital de Sydney”, não torna as coisas mais fáceis. Existe um problema muito grave de suicídio na pós-graduação. Eu imagino que a proporção de suicídios seja significativamente maior entre as pessoas que saem de seus lugares do que entre as pessoas que ficam neles. Quando você se recusa a chover no molhado, especialmente quando você pertence a uma categoria minoritária - quando você tem a pele escura mais escura do que a média, quando você é do gênero feminino, quando você é do Terceiro Mundo -, a academia pode deixar subitamente de ser um ambiente formidável de trocas intelectuais para se tornar um beco escuro, com cheiro de mijo, onde gangues satisfazem sua sede de sangue.

Então você tem que se proteger - talvez não fisicamente, mas quase com certeza psicologicamente. A gente tem que lembrar do que o Porchat falou em seu famoso mea culpa. Os professores estão alimentando ou matando os impulsos filosóficos dos estudantes? Talvez ele tenha usado aqui palavras fortes demais, é verdade. Mas talvez ele não tenha usado palavras suficientemente fortes. É difícil saber. Seja como for, o fato é que o seu pedido de desculpas dá a entender que ele empunhou o taco de beisebol com frequência. Talvez com boas intenções. Mas não necessariamente com boas consequências.

Parece evidente que você relatou um caso de dissonância cognitiva institucional. Estou me referindo justamente a este estranho fenômeno, que nada tem de racional - apesar de ser situado no seio da intelectualidade. Ou seja, o confronto de uma mente colonizada com uma ideia arguta, mas oriunda de uma posição desprivilegiada do globo, gera um efeito confuso - o horror emocional, quase que imunitário, que você relatou. Isso é evidentemente grave. Não somente para nossos alunos de filosofia, mas para a intelectualidade brasileira como um todo, e, por fim, para a nossa capacidade de independência política. Na sua perspectiva, este é um fenômeno que ocorreu de dentro da academia para a nação - ou, pelo contrário, foi transplantado da nossa nação para a academia?

Acho que você tocou aqui no centro da questão. A gente não sofre apenas de falta de autonomia intelectual, mas também, e isso é o mais importante, de falta de autonomia política - e também de falta de autonomia econômica, tecnológica, legal, policial e militar. Não temos controle sobre o nosso território. Não temos controle sobre o nosso futuro. Não temos sequer controle sobre o nosso passado. Fazemos parte do quintal dos Estados Unidos. É assim que eles se referem aos países da América Latina, como parte do seu quintal, do seu backyard. Recentemente, a Fox News, um dos mais influentes programas de notícias dos Estados Unidos - e também um dos mais patéticos 
-, referiu-se à Guatemala, El Salvador e Honduras como "países mexicanos". Temos aqui uma organização formadora de opinião - e que trabalha essencialmente com informação - reescrevendo a geografia, reordenando o mapa do mundo. Mas não há realmente nada de surpreendente aqui. O que a Fox News fez foi apenas dar voz àquilo que seus telespectadores sentem - e o que eles sentem é que a América Latina é, sim, o backyard dos Estados Unidos. Os Estados Unidos têm o direito de fazer o que quiserem com o seu quintal. Eles podem inclusive reorganizá-lo. Eles podem arrancar todas as árvores e pavimentar tudo. Eles podem até chamar a piscina de "churrasqueira" e a churrasqueira de "piscina". Eles podem fazer o que quiserem - e eles realmente fazem o que querem. Evidentemente, não tem o menor sentido falar em "países mexicanos". Do ponto de vista da verdade, não tem o menor sentido. Mas aquilo que se sente tem muito mais força do que a verdade - especialmente aquilo que se sente na maior potência militar do mundo. E aquilo que se sente é que todos os países ao sul da fronteira dos Estados Unidos são países mexicanos. O mundo externo está subordinado ao mundo interno. Os Estados Unidos investem anualmente em suas forças armadas um valor equivalente ao PIB de dez Guatemalas. Ou de trinta El Salvadors. Ou de trinta Honduras. Então eles podem reordenar o seu quintal. Eles podem fazer o seu ponto de vista prevalecer. Eles podem fazer o seu sentimento de vista prevalecer. A verdade existe, sim. Mas ela já não tem nenhuma credibilidade. Nem mesmo entre acadêmicos. E para os militares, ela é o produto da força.

Evidentemente, Guatemala, El Salvador e Honduras não são os únicos países mexicanos. O Brasil também é um país mexicano. Nós, brasileiros, também somos mexicanos. E colombianos. E venezuelanos. E haitianos. Achamos que somos todos Charlies Hebdo, mas o fato é que somos todos Marielles Franco. O muro do qual Trump fala tanto - e que o ajudou a ser eleito - não é apenas um muro entre os Estados Unidos e o México. É um muro entre os Estados Unidos e toda América Latina - o que inclui o Brasil. É um muro entre os Estados Unidos e todo mundo subdesenvolvido. É um muro entre a casa grande e a senzala, entre os ricos e os pobres, entre a opulência e a miséria. E apesar de não estar fisicamente construído, ele já existe no plano subjetivo há muito tempo - e está cada vez mais alto.

A geografia do mundo que carregamos no peito é muito diferente da geografia do mundo dentro do qual vivemos. A subjetividade também tem que ser estudada geograficamente. Ou melhor, geopoliticamente. A backyardização da América Latina - e agora a sua mexicanização - não é um puro devaneio, um puro delírio, um puro efeito da criatividade das nossas representações, das nossas Vorstellungen. Há aqui um 
projeto político. Até porque o muro entre eles e a gente é um muro poroso. Não se trata realmente de um muro que não deixa nada passar, mas de um filtro - que deixa passar o que interessa e bloqueia o que não interessa. Os países ricos não querem se isolar completamente dos países pobres - assim como a casa grande não quer se isolar completamente da senzala. Por exemplo, há um fluxo constante de órgãos vitais dos países pobres para os países ricos. As pessoas efetivamente vendem seus rins por migalhas. Então apesar de não sermos bem-vindos, nossos rins são bem-vindos, muito bem-vindos. Os muros burocráticos e legais que estão aí só impedem a passagem de pessoas. Não de rins, não de riquezas. Só de pessoas, de pessoas inteiras. O medo que se tem é das pessoas - e do que elas têm a dizer.

Mas o que veio primeiro, a nossa subserviência intelectual ou a nossa subserviência política? É tentador dizer que as duas coisas sempre caminham juntas o que é verdade - e que, portanto, não tem sentido perguntar qual delas veio primeiro. Mas acho que se olharmos para a década de 1960, que mudou drasticamente os rumos do Brasil, e que está agora se repetindo, a resposta é bastante clara: a subserviência política veio primeiro. É preciso lembrar que no início da década de 1960 - antes do golpe de 1964, que nos colocou firmemente no backyard dos Estados Unidos -, havia um enorme clima de otimismo no Brasil. O país tinha acabado de ganhar uma nova capital. Economicamente, as coisas estavam indo muito bem, maravilhosamente bem. E Brasília não foi apenas uma obra de engenharia fenomenal, foi também um feito artístico sem igual. Até hoje Oscar Niemeyer é estudado no mundo todo. E foi nesse clima de otimismo que a Universidade de Brasília começou a ser construída. Ela atraiu os professores mais idealistas do país. A ideia original era aprofundar o diálogo entre a academia e o governo, para que os dois trabalhassem juntos na resolução dos mais diversos - e urgentes - problemas socioeconômicos. Afinal, a gente tinha na época, como tem ainda, apesar do nosso estranho presidente negá-lo, um problema muito sério de fome e miséria. E o que aconteceu um ano depois do golpe militar? A UnB perdeu $80 \%$ do seu quadro de professores, incluindo Oscar Niemeyer. A maior parte deles pediu demissão como forma de protesto. A ditadura colocou um ponto final no diálogo entre a academia e o governo.

A gente tem que pensar seriamente se a gente quer finalmente se levantar e andar com as próprias pernas ou se a gente quer continuar sendo parte do quintal dos Estados Unidos. Se deixarmos o Facebook e o WhatsApp decidirem nossas eleições, se deixarmos os Bolsonaros e Weintraubs da vida dizerem o que pode e o que não pode ser estudado nas universidades, se deixarmos o planejamento econômico do país nas mãos de Chicago boys como Paulo Guedes - e ele não é um Chicago boy qualquer, mas um Chicago boy que trabalhou no Chile depois da derrubada de Salvador Allende -, o negócio não vai funcionar. A primeira coisa que um país precisa fazer para poder um 
dia andar com as próprias pernas é pensar com a própria cabeça. Não foi à toa que a ditadura tratou de reformar a universidade brasileira. E não é à toa que uma nova reforma já está em curso. A universidade tem uma enorme importância estratégica, coisa que os Estados Unidos sabem muito bem. Uma população crítica e idealista - isto é, uma população que não se deixa reduzir a uma coleção desordenada de indivíduos preocupados com o próprio umbigo, mas que efetivamente pensa, e pensa em termos coletivos - é a última coisa que os Estados Unidos querem ter no seu backyard. 